\title{
Study on the Influence of Winter Olympic Games on Sports Information Work in China
}

Tao Liu

Sports Sociology and Humanities, School of Sports Science, Nantong University, Nantong 226019, China

\begin{abstract}
The holding of winter Olympic Games in China indicates that China's sports has achieved a great degree of progress. At the same time, it also has a great impact on the sports information work. It will promote a great improvement in sports information access, information services and other aspects, as well as greatly stimulate the progress of sports information work. Therefore, this paper will emphatically analyze the impact on sports information work for holding the winter Olympic Games in China.
\end{abstract}

Key words: Winter Olympic Games, sports information, influence of work.

Successful applying for the 2012 winter Olympic Games of Beijing and Zhangjiakou in 2013 has encouraged the great ambition of majority of sports athletes, created opportunities for sports development in China and provided chances for the development of sports information work [1-7]. Because the holding of winter Olympic Games would require support from sports information, it has become an important work of sports departments at all levels to adjust and optimize the sports information work, which includes increasing the action strength, building a perfect sports information organization, innovating the theory of sports information science and improving sports information services quality. Therefore, it will have a positive impact on sports information work for China to hold the winter Olympic Games.

\section{Instruction of Sports Information}

The concept of information is always developing. Information was regarded as the content of library information in 1980s. Under the background of booming development of science and technology, the implication of information was expanded in 1990s. With the progress of times and the development of science and technology, sports information has been

Corresponding author: Tao Liu, Dr., lecturer, research field: sports humanistic sociology. defined as the representative that reflects sports rules and imagination after words, numbers, and signals are conveyed and processed. Therefore, sports information includes sports management and decision information, sports teaching information, sports technology information, and sports competition information and so on. In summary, based on relevant literatures, it is obvious that sports information is practical. China should correctly define the concept of sports information when holding Winter Olympics, and adjust sports information tasks scientifically and reasonably from the perspective of understanding of sports information, which will promote the development and progress of sports information work in the true sense.

\section{Development Status of Sports Information Work in China}

Combined with the actual situation of sports information work in China in recent years, the development of sports information has the following trends.

\subsection{Certain Expansion of Domestic Sports Information Work Area}

Sports information work, which started from the 1980s, has transformed from the mode of a single 
transmission and acquisition to a new mode of multiple channels sports information service with the influence of computer technology, network technology, information technology and other science and technology. Moreover, with the attached significance of governments, national sports departments at all levels and physical education school, the sports information work has been paid great attention in recent years, which makes the sports information work be expanded to a large extent.

\subsection{Further Academic Research of Sports Information}

In the primary stage of sports information development, the academic research mainly focuses on the aspects of sports training, sports scientific research and sports teaching, which makes the academic research of sports information limited and not comprehensive. With the rapid development of China's economy, science and technology, the sports information research has made a great progress. The research goal set is more thorough, research object is more widespread, research method is more diverse, which promotes the academic research of sports information to develop in a direction of informatization, networking and diversified [8-14].

\subsection{Gradually Perfect of Sports Information Organization}

Business of sports information center of the reformed State Administration of Sports has been continuously deepened; various project management centers of the State Administration of Sports have formed the information department; libraries of physical education colleges and universities have strengthened the resources construction. All these conditions make sports information organization gradually perfect. In the specific development of sports information, service model of sports information is appropriately adjusted on the basis of sports development demand, the service quality of sports information is improved, so as to provide important basis for the optimization and adjustment of sports activities. Therefore, in order to complete sports information organizations and to bring their effects into full play, relevant departments and personnel should adjust the structure of these organizations by combing with the current situation of sports information under the favorable situation when these organizations are improved gradually to make these organizations deal with sports information affairs, to arrange proper staff in the proper posts, to raise the use rate of sports information resources, and to bring the effect of sports information into full play.

\subsection{Many New Academic Outcomes of Sports Information Are Made in China Recently}

From the perspective of the current situation of sports information research, China innovates basic theories and application theories of sports information to some degree, laying a solid foundation for the expansion and innovation of sports service methods and approaches, providing favorable conditions for the optimization development of academic sports journal editing and publication, promoting the further development of sports information education, and speeding up digital construction of sports information resources. Therefore, these academic outcomes of sports information are applied ones. However, from the perspective of Winter Olympics and sports career development need, the theoretical knowledge of sports information could not support relevant tasks and Winter Olympics yet, and could not make contributions to sports career development [3]. Therefore, relevant researchers should devote themselves to researching sports information; make breakthroughs and innovation; make new academic outcomes; promote the further development of sports career.

\section{Problems and Challenges Faced in the Development Sports Information in China}

In spite of the great development of sports information field in our country, the constantly 
internal and external environment influences, together with many other factors, make the development of sports information in China encounter many problems and challenges.

\subsection{Lagging Theoretical Research of Sports Information Science}

Theoretical works of sports information about its theoretical research and development are rare and published in early days, and there is almost no theory breakthrough and works updating in the sports information in recent years. Under such a circumstance, the sports information work in our country is in the double influence of the modern information age and the traditional sports information theory. The further innovation and development of sports information work is quite difficult. Thereby, relevant departments and experts in charge of sports information should attach great importance to the issue that theoretical research of of sports information science lags behind [15-18].

\subsection{Diversified Demand Puts Forward Higher} Requirements for Sports Information Work

With the application of network technology, information technology, computer technology and other science and technology, people pay more and more attention to intelligent life. Correspondingly, demands of sports information users for sports information have also changed, that is to require the sports information services to be diversified. In order to meet the demands of the majority of sports information users, improving the work requirements has become an inevitable situation in the process of developing sports information work. Only by high demand of sports information work can it change the status of sports information staff, status of sports information technology and sports information service, thus efforts to innovate and develop sports information services, meet the needs of sports information users [19-25].

\subsection{The Professional Talent Team Construction Should Be Improved}

From the perspective of the practical situation of domestic professional talent team construction, sports information talents emerge in large numbers indeed, but it does not mean that the professional high-quality and high-skill talent team has been built. That is because most of relevant personnel are not professional enough, with low comprehensive quality and poor professional skills, so they will have difficulties in work and the relevant sports information transmission, application, and contribution will not good enough, which will not be beneficial to the healthy development of sports information work. It is certain that there are many factors that sports information personnel fail to meet the requirement of the talent team construction. Therefore, relevant departments should find the major reasons to make the effective strategies to strengthen their education and training and to improve their level [26-29]. In addition, sports information personnel's lack of professional knowledge, skills, and low quality are major important reasons which restrict the team construction, so relevant departments should pay more attention to it in the subsequent sports information work.

\subsection{The Unified Basic Technical Standards Should Be Confirmed in the Process of Resource Development}

At present, the unified, scientific, and reasonable basic technical standards are lacked in the current sports information resource development, which has negative influence on sports information work to some degree. Concretely speaking, sports information personnel do not integrate relevant resources according to the unified basic technical standards when collecting sports information. As a result, some resources in other formats will not be applied effectively; the effect of sports information will not be improved; sports information will not lay a solid foundation for the sports career optimization. Therefore, the lack of the unified basic technical 
standards, to some degree, restricts the application of sports information and has negative influence on sports information work, so relevant departments should make the unified basic technical standards in the subsequent work [30-35].

\section{Influence on Sports Information Work for China to Hold the Winter Olympic Games}

Under the circumstance that our sports information work faces many problems and challenges, the holding of winter Olympic Games will make a positive and active impact on sports information for China, promote the sports information work to adjust and optimize correctly, solve problems and face up to challenges, so as to develop well.

\subsection{The Holding of Winter Olympic Games Promotes} the Theoretical Innovation of Sports Information Science

Compared with the developed countries in Europe and America, the relatively low level for theory and practice of sports information in our country is not conducive to promoting the development of sports information work. However, we actively reference to the theory and practical experience of foreign countries in holding the winter Olympic Games, which not only lays a solid foundation for the successful hosting of the Winter Olympics Games, but also provides a basis for the theoretical innovation of sports information in China. Therefore, by learning form the foreign sports theory and combining the national sports characteristics, the theoretical research of our sports information science would acquire new sports information science theories that are suitable for the development of sports information in China.

\subsection{The Holding of Winter Olympic Games Promotes the Construction of Sports Information Institutions in China}

We need to take advantages of sports information and give full play to the academic role of sports information, so as to provide assistants for Beijing to hold the winter Olympic Games. In order to scientific and reasonably apply the sports information, sports departments at all levels of our country should actively carry out the establishment of sports information department, be responsible for sports information research, technology development of sports information, sports information services, thus to better support the holding of Winter Olympic Games [7]. So, the holding of Winter Olympic Games in China would promote the importance of sports information work and arouse the pace of establishing the sports information institutions at all levels of sports departments.

\subsection{The Holding of Winter Olympic Games Promotes} the Talents Cultivation of Sports Information

Support of sports information is needed to hold the winter Olympic Games, but the support of talents in sports information is more needed. With the support of talents in sports information, the research of sports information, technology research of sports information and sports information services can be completed with high quality, thus to create conditions for the successful holding of the winter Olympic Games. Therefore, sports related departments should fully realize the importance of talents cultivation of sports information, increase the training intensity of sports information technology professional knowledge, and enhance the professional knowledge level of sports information staff. Moreover, they should also organize to edit textbooks and journals related to the information, provide learning resources to sports information personnel, thus actively to cultivate excellent and professional sports information talents [35].

Winter Olympics will promote international exchange and cooperation of sports information.

China will hold Winter Olympics in 2022, which will promote the international exchange and cooperation of sports information. The reasons are as follows: 
(1) Foreign digital sports information resources will be led in. In order to hold Winter Olympics successfully, Chinese sports information organizations will lead in foreign advanced digital sports information resources, and use these resources in flexible and diversified ways to realize the exchange and combination between domestic and foreign sports information, to provide true, effective, and practice sports information, and to lay a solid foundation for Winter Olympics. Therefore, Winter Olympics will promote international sports information exchange and collaboration.

(2) Construction of sports information websites will promote foreign exchange. In order to make Chinese people acquire the latest news of Winter Olympics at the first time, relevant departments should build sports information websites to convey relevant information. Foreign countries are interested in the process of Winter Olympics in China as well, so both Chinese version and foreign language versions of information websites should be provided, to provide a platform for foreigners to talk about sports information [9], which will be favorable to the improvement of sports information.

(3) Strengthening digital construction of sports information resources will promote international collaboration. Digital technology of sports information resources is relatively mature in Europe and America, which could provide professional theoretical guidance for Chinese digital construction of sports information resources. In order to assure that Winter Olympics could be successfully held in China, sports information departments and personnel should refer to European and American digital technology of sports information resources, and scientifically and reasonably construct digital sports information resources by combining with the practical situation of application of sports information in China, to make these digital resources play an important role in Winter Olympics and to create conditions for international sports information exchange [10].
Therefore, Winter Olympics makes the exchange and collaboration between Chinese and foreign sports information possible.

\section{Conclusion}

Sports departments at all levels of our country would fully realize the importance of establishment of sports information organization, talents cultivation of sports information, theoretical innovation of sports information science under the background of China's successful applying for the Winter Olympics Games. They would take more forcefully actions to change the status of sports information work, adjust and optimize the sports information work. Also, efforts would be made to solve problems and combat challenges. Therefore, it has an more positive and active impact on sports information for China to hold the Olympic Games.

\section{Reference}

[1] Wang, Y. B. 2015. "Influence of the Winter Olympic Games on the Sports Information Work in China." Modern Information 35 (4): 139-41.

[2] Xin, L., Jing, H. J. 2013. "Discussion on How to Do a Good Job of Sports Information in Jiangsu in the New Period.” Journal of Nanjing Institute of Physical Education (Natural Science) 12 (6): 89-91.

[3] Fan, B. 2008. Study of Sports Information Work in the Post-Olympic Games Period. In Proceedings of 2008 National Sports Information Conference, 121-2.

[4] Zhang, J. N., and Deng, W. J. 2001. "Analysis of Influence of Knowledge Economy on Sports Information Work in China." Journal of PLA Institute of Physical Education 20 (1): 20-3.

[5] Wang, X. F. 2014. “Analysis on Sports Information Homogenization Problems on Chinese Large Portal Websites.” Sports Culture Guide 3: 196-9.

[6] Liu, X. S., and Hu, M. J. 2010. "The Model Research that Sports Information Serves Competitive Sports.” Journal of Chengdu Sports Institute 33 (6): 55-8.

[7] Sun, Y. T. 2001. "Discussion on Necessity and Possibility of Military Sports Information Work.” China Sports Science and Technology 37 (1): 42-4.

[8] Zhou, D. S., and Huang, X. H. 2010. "Research on Sports Information Resource Share Model and Operation Mechanism under Network Environment-Take the Sports Information Resource Construction and Share 
Network Framework of the General Sports System as the Example.” Journal of Guangzhou Sport University 29 (5): 16-21.

[9] Li, K. Y., and Deng, X. 2010. "Practice of Sports Information Culture Communication and Analysis on Literature Communication-The Illustration on Olympics Library.” Library Development 4: 43-6.

[10] Li, L., and Tian, L. 2015. "The Research of College Sports Information Management System Based on Component and the Application in Student's Management Work.” International Journal of Hybrid Information Technology 8 (3): 375-86.

[11] Sun, T. H. 2014. "Research and Design on Sports Meeting Management System Based on Information Technology.” Advanced Materials Research 971-3: 1953-7.

[12] Yan, H., and Wang, T. 2013. "Study on College Physical Education Management Information System Based on Support Vector Regression.” Research Journal of Applied Sciences Engineering \& Technology 6 (22): 4254-8.

[13] Xu, J. M. 2014. "The Research of Ideological and Political Work Management System for College Students Based on J2EE.” Applied Mechanics \& Materials 687-91: 2533-6.

[14] Slawson, S. E., Conway, P. P., and Cossor, J. 2013. “The Categorisation of Swimming Start Performance with Reference to Force Generation on the Main Block and Footrest Components of the Omega OSB11 Start Blocks.” Journal of Sports Sciences 31 (5): 468-78.

[15] Tian, C. L .2013. "Design and Research of University Fitness Club Operation Management Information System Based on Network Platform.” Shandong Sports Science \& Technology.

[16] Xu, J. M. 2014.”The Research of Ideological and Political Work Management System for College Students Based on J2EE." Applied Mechanics \& Materials 687-691: 2533-6.

[17] LV, S. J., and Pei, X. C. 2015. "Basic Rules and Reform Research on the Event Development of Winter Olympic Games.” China Winter Sports.

[18] LU, S. J., Lin X. M., and Chen, G. R. 2004. "Basic Rules of Olympic Event Development and Research on Event Reform.” Journal of Beijing University of Physical Education.

[19] Joshi, C., Darwent, C., and Giese, K. 2009. "Transportation Modeling for the 2010 Winter Olympic Games." Conference \& Exhibition of the Transportation Association of Canada_-Transportation in A Climate of Change.

[20] Hatfield, L. M., and Johnson, J. T. 2012. “A Discussion of Work Family Conflict and Related Theories in NCAA Division I Sports Information Professionals.” Journal of Contemporary Athletics 6 (1): 2.
[21] Mazerolle, S. M., Bruening, J. E., and Casa, D. J. 2008. "Work-family Cconflict, Part I: Antecedents of Work-family Conflict in National Collegiate Athletic Association Division I-A Certified Athletic Trainers.” Journal of Athletic Training 43 (5): 505-12.

[22] Hatfield, L. M., and Johnson, J. T. 2013. “An Examination of Work Family Conflict in NCAA Division III and NAIA Sports Information Professionals.” Journal of Applied Sport Management.

[23] Mazerolle, S. M., Ferraro, E. M., and Eason, C. M. 2013. "Factors and Strategies Contributing to the Work-Life Balance of Female Athletic Trainers Employed in the NCAA Division I Setting.” Athletic Training \& Sports Health Care the Journal for the Prac. 5 (5): 211.

[24] Mazerolle, S. M. 2008. "Work-family Conflict, Part II: Job and Life Satisfaction in National Collegiate Athletic Association Division I-A Certified Athletic Trainers.” Journal of Athletic Training 43 (5): 513-22.

[25] Baugh, C. M., Kiernan, P. T., and Emily, K. 2015. "Frequency of Head Impact Related Outcomes by Position in NCAA Division I Collegiate Football Players.” Journal of Neurotrauma 32 (5): 315-26.

[26] Shirazi, A. 2003. "The Perceptions of Head Athletic Trainers in NCAA Division I, II, and III Member Institutions toward the Status of Alcohol Tobacco and Other Drug (ATOD) Prevention and Education Policies.” Dissertation Abstracts International 64 (12) Section B: 6043.

[27] Greve, L., and Dyson, S. J. 2014. “The Interrelationship of Lameness, Saddle Slip and Back Shape in the General Sports Horse Population.” Equine Veterinary Journal 46 (6): 687-94.

[28] Mccann, S. 2014. "So You'd Like a Sport Psychology Consultant to Work With Your Team? Three Key Lessons Learned from Olympic Teams.” Olympic Coach 25 (3): 26.

[29] Rennie, C. 2014. “Agency Information Collection (VA National Veterans Sports Programs and Special Event Surveys Data Collection) Activity Under OMB Review.” Federal Register 79 (47): 13741.

[30] Krasilnikov, V. L., Erlikh, V. V., and Mirgorodskaya, E. V. 2014. "New Approaches to Interpretation of Information Space in Sports Training of Swimmers on The Basis of Inte Gration of Instrumental Technologies.” Journal of Capital University of Physical Education and Sports.

[31] Mclamb, D. 2012. “Agency Information Collection (Authorization To Substitute a Claim of a Deceased Claimant); Activities Under OMB Review.” Federal Register (164): 43228.

[32] Koufaki, D. P., and Kouidi, E. 2010. "Current Best Evidence Recommendations on Measurement and 
Interpretation of Physical Function in Patients with Chronic Kidney Disease.” Sports Medicine 40 (12): 1055-74.

[33] Ravana, D., Raman, S. N., and Ooi, P. P. 2007. “Analysis, Design and Development of Sports Information Portal: Supporting Participation in Sports Events.” Journal of Applied Sciences Research (8): 757-63.

[34] Guah, M. 2009. "Case Study III: VLITP in Public
Transport-Implementing OV-Chipcard in The Netherlands." Managing Very Large It Projects in Businesses \& Organizations.

[35] Nan, X. H., Cui, W. F., Yang, B. F., and Zheng, X. F. 2006. "Affection to the City Development and Winter Sports with Applying for the Winter Olympic Games of Harbin.” Journal of Harbin Institute of Physical Education 24 (5): 7-9. 